\title{
PEMBANGUNAN WC UMUM DI PURA DADIA TUTUAN DESA LES KECAMATAN TEJAKULA BULELENG
}

\author{
N. Gunantara ${ }^{1}$, G.M.A. Sasmita², N.K.A. Dwijendra ${ }^{3}$, A.A.D.P. Dewi ${ }^{4}$, I.M. Mataram ${ }^{5}$
}

\begin{abstract}
ABSTRAK
Pura merupakan tempat yang disucikan oleh umat Hindu. Sehingga keberadaannya tidak dilengkapi dengan WC (Water Closet) umum. Hal ini disebabkan WC umum dianggap mengotori pura. Tetapi dengan perkembangan bangunan di sekitar areal pura maka disekeliling areal pura sudah ada rumah-rumah penduduk dimana sebelumnya masih berupa lahan kosong atau lahan pertanian. Dengan demikian para pemedek yang berada di pura apabila ingin buang air kecil akan mengalami kesusahan mencari tempat. Sementara ini, para pemedek yang berada di pura untuk melakukan persembahyangan atau ada kegiatan lain, apabila ingin buang air kecil terpaksa pinjem WC di rumah penduduk. Kejadian ini sudah dilakukan sejak dari dulu. Apabila hal ini terus dilakukan maka akan menggangu yang punya rumah serta para pemedek merasa tidak nyaman. Kondisi ini terjadi juga di Pura Dadia Tutuan. Solusi dari permasalahan ini maka krama warga dadia sesuai dengan hasil paruman maka berinisiatif untuk membangun WC umum yang khusus untuk tempat buang air kecil bukan untuk buang air besar. Prajuru dan Krama Pura Dadia Tutuan melaksanakan pertemuan untuk membahas dan memutuskan letak lokasi WC umum tersebut bertepatan dengan Hari Raya Galungan. Letak lokasi WC umum berada tepat di sebelah Pura Dadia Tutuan. Pemilihan lokasi ini karena tanah/area tersebut dimiliki oleh salah satu Krama Pura Dadia dimana tanah tersebut masih kosong dan pemilik sudah menyetujui pada pertemuan tersebut. Pembanguan WC Umum sudah dilakukan oleh warga Krama Pura Dadia Tutuan yang sudah ditunjuk pada pertemuan. Hasil Bangunan WC Umum tersebut sudah diserahkan kepada Krama Pura Dadia Tutuan melalui Prajuru, Warga, dan Tim Pengabdian.
\end{abstract}

Kata kunci: Pura Dadia Tutuan, Desa Les, desain, implementasi, WC umum.

\begin{abstract}
The temple is a place that is purified by Hindus. So that its existence is not equipped with public toilet (Water Closet). This is because public toilets are considered to pollute the temple. But with the development of buildings around the temple area around the temple area there have been houses where previously they were still in the form of vacant land or agricultural land. Thus the pemedek who are in the temple if you want to urinate will have difficulty finding a place. Meanwhile, the pemedek who are in the temple to do prayers or other activities, if they want to urinate, they are forced to borrow a toilet in a resident's house. This incident has been done since a long time ago. If this continues, it will disrupt the owner of the house and the pemedek feel uncomfortable. This condition also occurs in Dadia Tutuan Temple. The solution to this problem is that the citizens' dwellings in accordance with the results of the paruman then took the initiative to build public toilets specifically for urination rather than to defecate. Prajuru and Krama Dadia Tutuan Temple held a meeting to discuss and decide where the location of the public toilet coincided with Galungan Day. The location of the public toilet is right next to Dadia Tutuan Temple. The choice of location is because the land /
\end{abstract}

\footnotetext{
${ }^{1}$ Program Studi Teknik Elektro Fakultas Teknik Universitas Udayana, gunantara@unud.ac.id.

${ }^{2}$ Program Studi Teknologi Informasi Fakultas Teknik Universitas Udayana

${ }^{3}$ Program Studi Arsitektur Fakultas Teknik Universitas Udayana

${ }^{4}$ Program Studi Teknik Sipil Fakultas Teknik Universitas Udayana

${ }^{5}$ Program Studi Teknik Elektro Fakultas Teknik Universitas Udayana
} 
area is owned by one of the Krama Dadia Tutuan Temple where the land is still empty and the owner has agreed to the meeting. Public toilet construction has been carried out by residents of Krama Pura Dadia Tutuan who had been appointed at the meeting. The results of the Public Toilet Building have been submitted to Krama Dadia Tutuan Temple through Prajuru, Residents, and Community Service Team.

Keywords: Dadia Tutuan Temple, Les Village, design, implementation, public toilet.

\section{PENDAHULUAN}

Masyarakat Desa Les memiliki tingkat keyakinan yang sangat tinggi dan sangat agamis. Ini didukung oleh adanya bermacam-macam Pura dan adat istiadat. Selain Pura Puseh Panjingan yang merupakan bagian dari Gebog Satak, di Desa Les terdapat banyak Pura. Macam-macam Pura tersebut adalah Pura Tri Kahyangan Desa, Pura yang diempon Desa, Pura Dadia, Pura Merajan, dan Pura Keluarga. Pura Tri Kahyangan Desa yaitu Pura Desa/Bale Agung, Pura Puseh Panjingan, dan Pura Dalem. Pura yang diempon oleh masyarakat desa yaitu Pura Merajan Desa, Pura Dalem Gremet, Pura Dalem Swan Anyar, Pura Dangka, Pura Beji, Pura Sengguhu, Pura Gria, Pura Segara, dan Pura Naga. Sedangkan Pura Dadia diempon oleh sekelompok keluarga. Jumlah Pura Dadia di Desa Les lebih banyak dibandingkan Pura yang diempon oleh masyarakat desa.

Pura-pura tersebut tidak dilengkapi dengan WC (Water Closet) umum. Hal ini disebabkan WC umum dianggap mengotori pura. Tetapi dengan perkembangan bangunan di sekitar areal pura maka disekeliling areal pura sudah ada rumah-rumah penduduk dimana sebelumnya masih berupa lahan kosong atau lahan pertanian. Dengan demikian para pemedek yang berada di pura apabila ingin buang air kecil akan mengalami kesusahan mencari tempat. Sementara ini, para pemedek yang berada di pura untuk melakukan persembahyangan atau ada kegiatan lain, apabila ingin buang kecil terpaksa pinjem WC di rumah penduduk. Kejadian ini sudah dilakukan sejak dari dulu. Apabila hal ini terus dilakukan maka akan menggangu yang punya rumah serta para pemedek merasa tidak nyaman. Kondisi ini terjadi juga di Pura Dadia Tutuan.

Solusi dari permasalahan ini maka krama warga dadia sesuai dengan hasil paruman berinisiatif untuk membangun WC umum yang khusus untuk tempat buang air kecil bukan untuk buang air besar. Kami sebagai pengabdi terdorong hati nuraninya untuk melakukan pengabdian di Pura Dadia Tutuan untuk mewujudkan pembangunan WC umum tersebut. WC umum yang akan dibangun berupa bangunan minimalis dengan ukuran yang kecil dan ditempatkan pada areal jaba pura. Pembangunan WC umum ini sudah mempertimbangkan kesucian dan estetika dari pura tersebut. Sehingga keberadaan WC umum ini tidak dianggap mengotori pura dan mengganggu keindahan pura.

\section{METODE PELAKSANAAN}

Permasalahan yang terdapat di Pura Dadia Tutuan adalah tidak adanya tempat untuk melakukan buang air kecil untuk para pemedek yang berada di pura baik pada saat melakukan persembahyangan atau ada kegiatan lain. Solusi dari permasalahan ini maka krama warga dadia sesuai dengan hasil paruman maka berinisiatif untuk membangun WC umum yang khusus untuk tempat buang air kecil bukan untuk buang air besar. Kami sebagai pengabdi terdorong hati nuraninya untuk melakukan pengabdian di Pura Dadia Tutuan untuk mewujudkan pembangunan WC umum tersebut. WC umum yang akan dibangun berupa bangunan minimalis dengan ukuran yang kecil dan ditempatkan pada areal jaba pura seperti terlihat pada Gambar 1. Pembangunan WC umum ini sudah mempertimbangkan kesucian dan estetika dari pura tersebut. Sehingga keberadaan WC umum ini tidak dianggap mengotori pura dan mengganggu keindahan pura. 


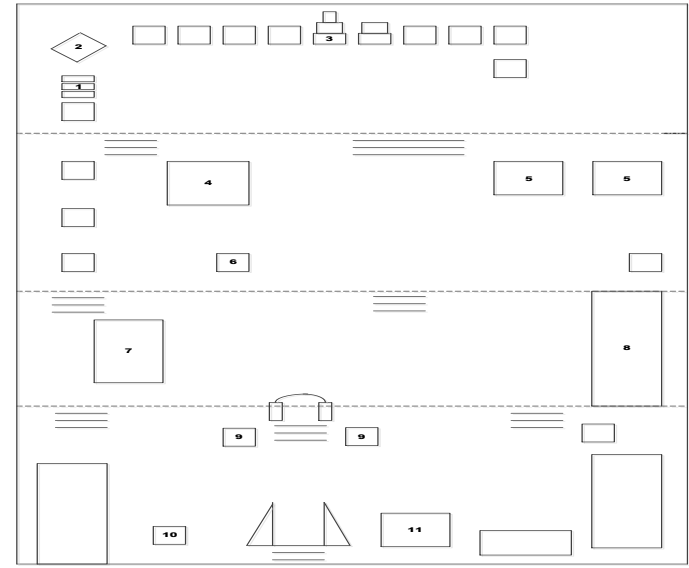

Gambar 1. Denah WC di Pura Dadia Tutuan

\section{HASIL DAN PEMBAHASAN}

Pembangunan WC umum yang akan dilakukan di Pura Dadia harus memperhatikan kesucian dan keindahan pura. Untuk itu perlu ditentukan letak lokasi WC umum yang akan dibuat. Sehingga Prajuru dan Krama Pura Dadia Tutuan melaksanakan pertemuan untuk membahas dan memutuskan letak lokasi WC umum tersebut yang dilaksanakan pada Rabu, 24 Juli 2019 bertepatan dengan Hari Raya Galungan yang dapat dilihat pada Gambar 2, Gambar 3, dan Gambar 4.

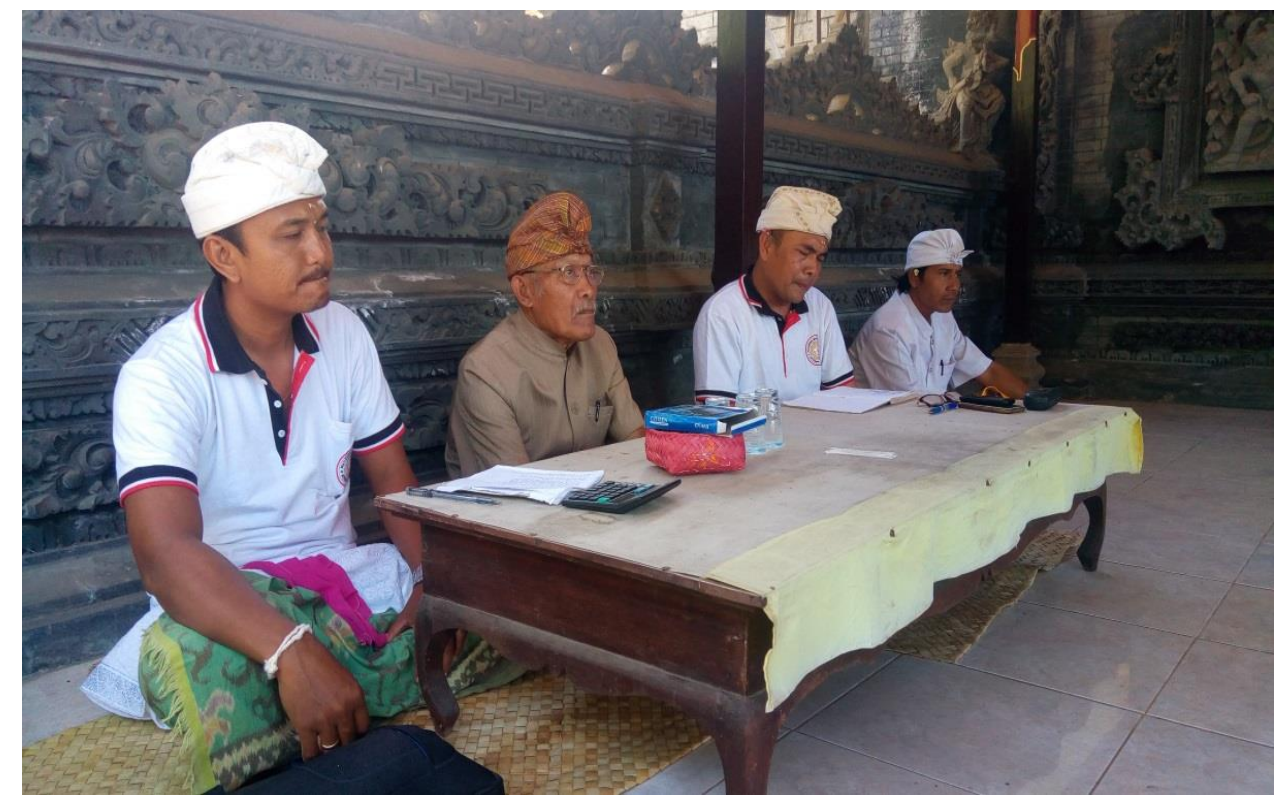

Gambar 2. Prajuru Pura Dadia Tutuan 


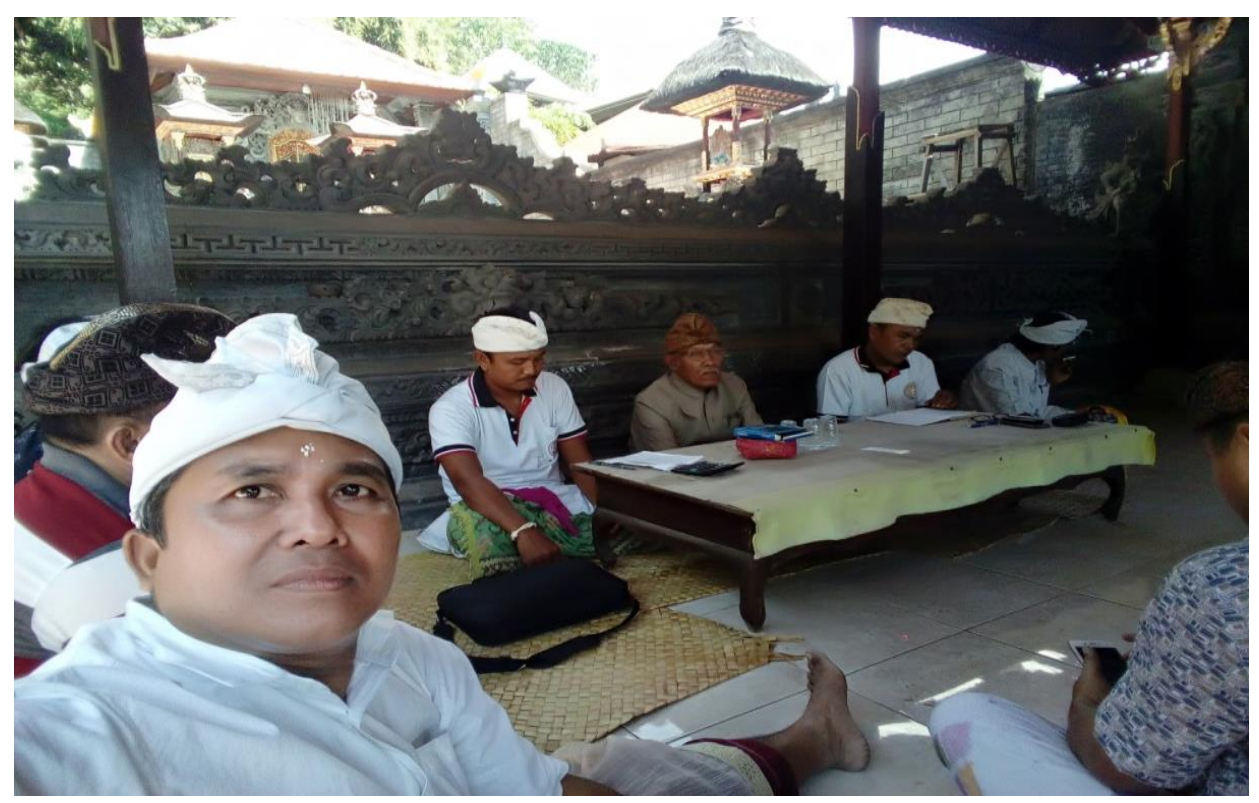

Gambar 3. Tim Pengabdian Pada Pertemuan

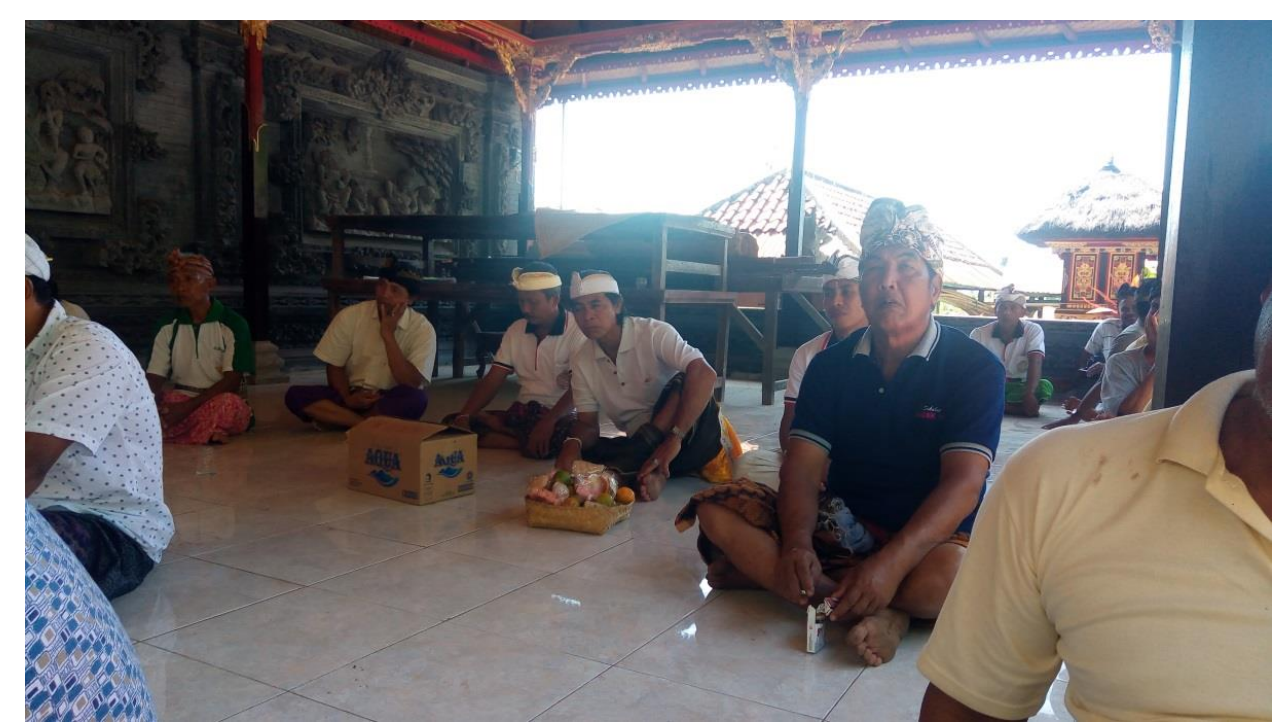

Gambar 4. Krama Pura DadiaTutuan

Pada pertemuan tersebut selain membahas dan memutuskan letak lokasi WC umum, kami Tim Pengabdian menyampaikan tentang adanya bantuan biaya untuk pembangunan WC umum tersebut dari Universitas Udayana melalui Program Udayana Mengabdi.

\subsection{Letak Lokasi WC Umum}

Hasil pertemuan tersebut memutuskan bahwa letak lokasi WC umum berada tepat di sebelah Pura Dadia Tutuan yang dapat dilihat pada Gambar 5 dan Gambar 6. Pemilihan lokasi ini karena tanah/area tersebut dimiliki oleh salah satu Krama Pura Dadia dimana tanah tersebut masih kosong dan pemilik sidah menyetujui pada pertemuan tersebut. 


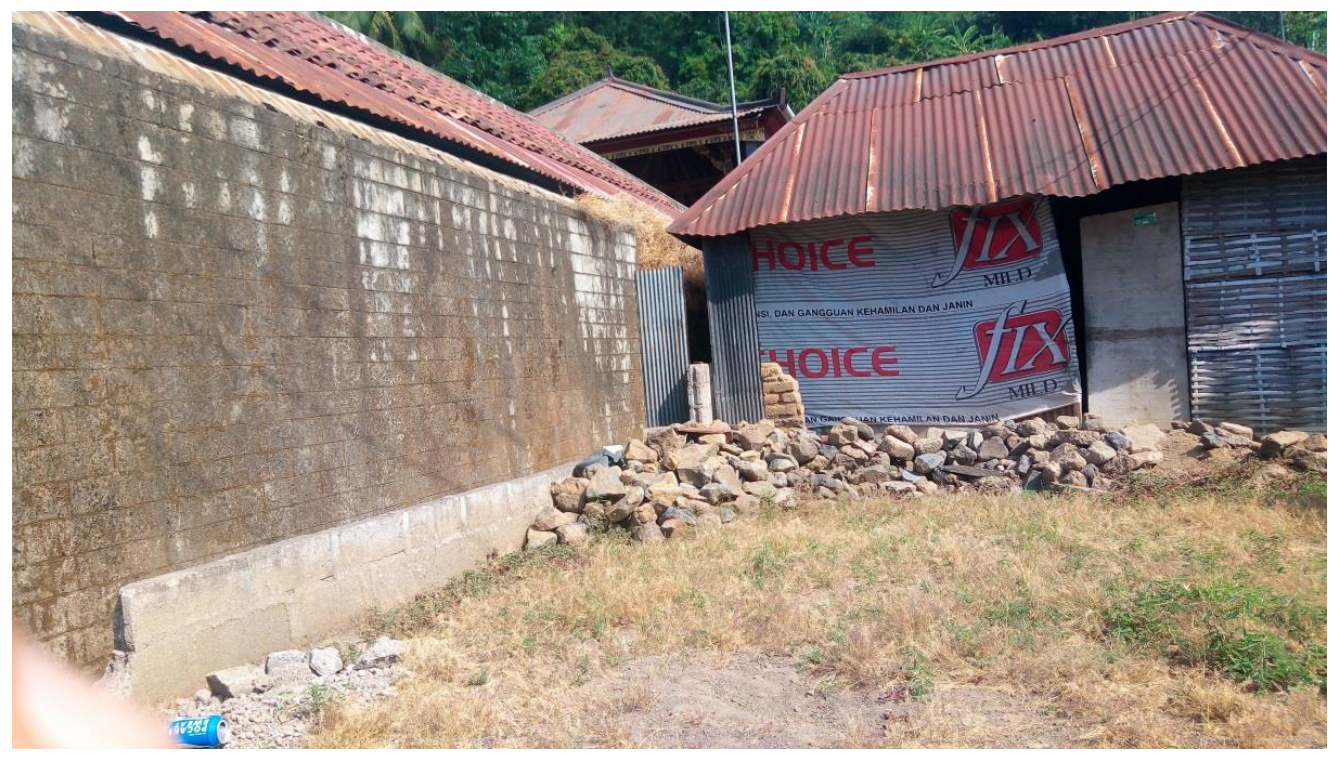

Gambar 5. Letak Lokasi WC Umum Dari Dekat

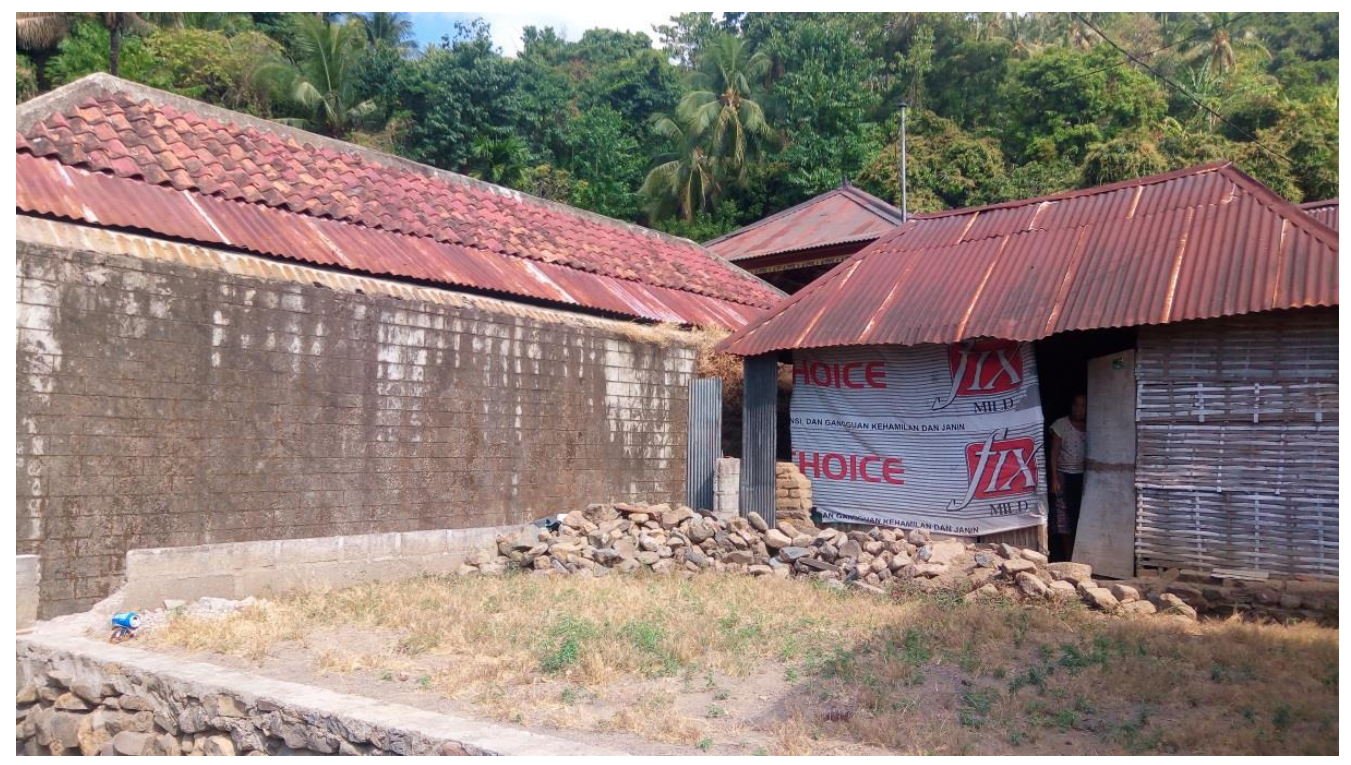

Gambar 6. Letak Lokasi WC Umum Dari Jauh

\subsection{Pembangunan WC Umum}

Setelah lokasi WC Umum ditentukan, maka langkah selanjutnya adalah proses pembangunan WC Umum. Pembangunan WC Umum tersebut dilakukan oleh warga dari Krama Pura Dadia Tutuan yang sudah ditunjuk pada pertemuan tersebut. Hasil dari pembangunan WC Umum tersebut dapat dilihat pada Gambar 7. 


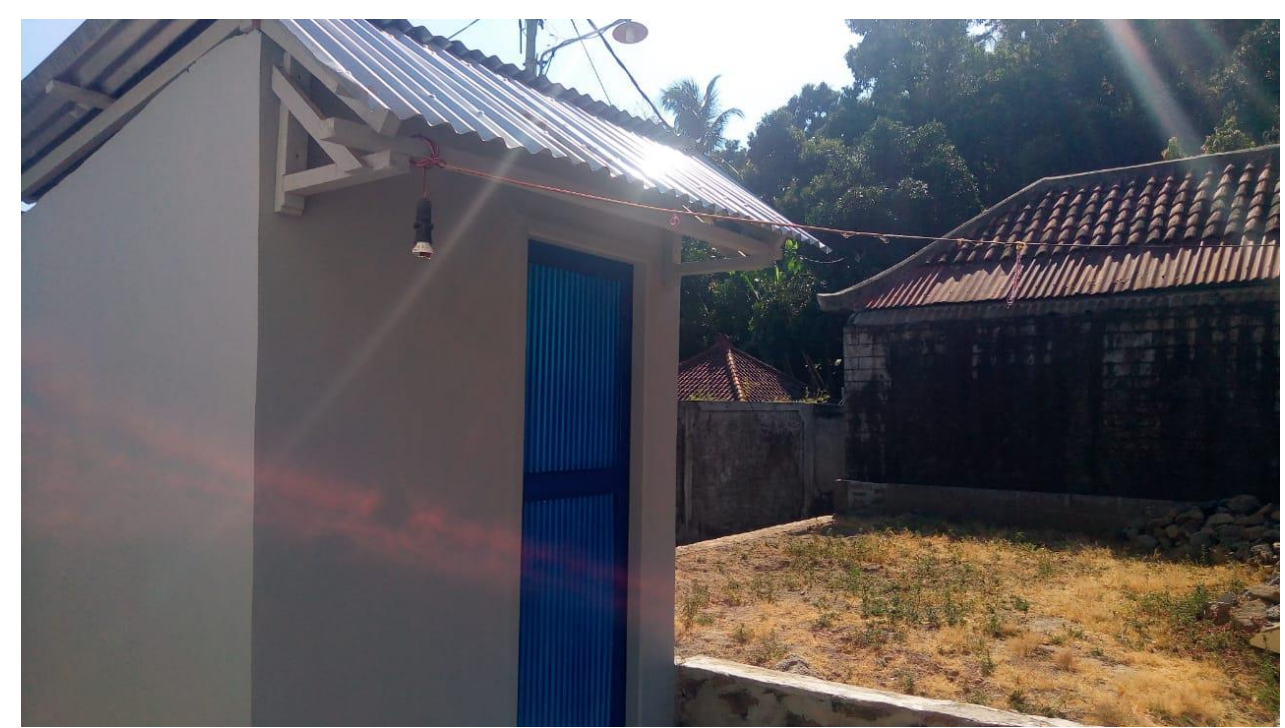

Gambar 7. Bangunan WC Umum

\subsection{Penyerahan Banguan WC Umum}

Bangunan WC Umum yang sudah melalui proses dan dilakukan pengawasan dalam mengerjakannya pada akhirnya dapat diselesaikan. Sehingga langkah selanjutnya dilakukan penyerahan Bangunan WC Umum tersebut kepada Krama Pura Dadia Tutuan melalui Prajuru Pura Dadia Tutuan. Penyerahan Bangunan WC Umum tersebut dihadiri oleh Kelihan, Wakil, Sekretaris, Bendahara, dan beberapa karma Dadia Tutuan. Pada saat penyerahan Bangunan WC Umum tersebut dihadiri juga oleh Tim Pengabdian. Penyerahan Bangunan WC Umum tersebut dapat dilihat pada Gambar 8 .

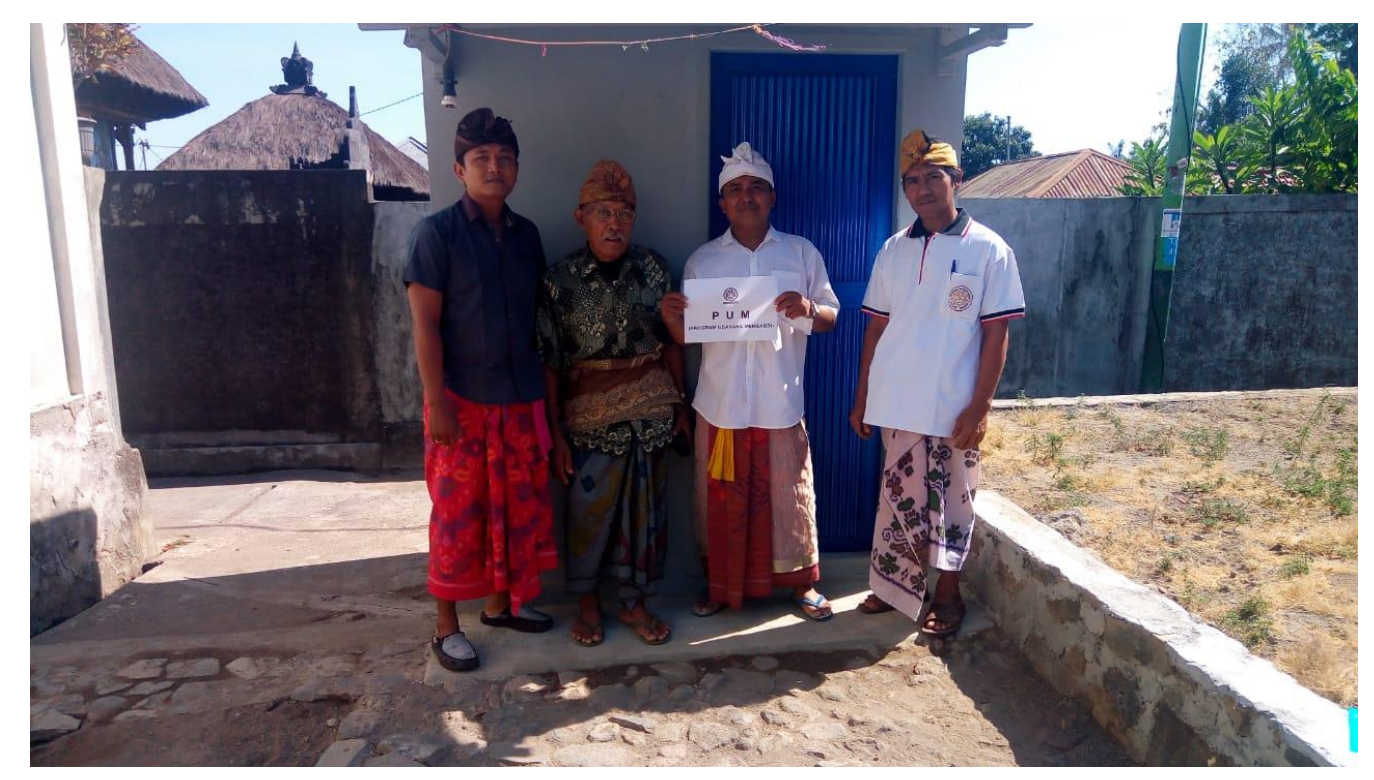

Gambar 8. Penyerahan Bangunan WC Umum 


\section{KESIMPULAN}

Dari hasil kegiatan pengabdian yang sudah dilakukan maka dapat dibuat kesimpulan sebagai berikut pertama, prajuru dan Krama Pura Dadia Tutuan melaksanakan pertemuan untuk membahas dan memutuskan letak lokasi WC umum tersebut yang dilaksanakan pada Rabu, 24 Juli 2019 bertepatan dengan Hari Raya Galungan. Kedua, letak lokasi WC umum berada tepat di sebelah Pura Dadia Tutuan. Pemilihan lokasi ini karena tanah/area tersebut dimiliki oleh salah satu Krama Pura Dadia dimana tanah tersebut masih kosong dan pemilik sidah menyetujui pada pertemuan tersebut. Pembanguan WC Umum sudah dilakukan oleh warga Krama Pura Dadia Tutuan yang sudah ditunjuk melalui pertemuan. Hasil Bangunan WC Umum tersebut sudah diserahkan kepada Krama Pura Dadia Tutuan melalui Prajuru, Warga dan Tim Pengabdian.

\section{UCAPAN TERIMA KASIH}

Tim pengabdian mengucapkan Terima Kasih kepada Universitas Udayana melalui Dana DIPA PNBP serta Krama Pura Dadia Tutuan terkait dan masyarakat Desa Les atas bantuan dan kerjasamanya.

\section{DAFTAR PUSTAKA}

http://tejakula.bulelengkab.go.id/?sik=kantor\&bid=cd9d7db20f82935fcd09b20f3f2012f2 Darmawan, E. dan Rosita, M. (2016), Konsep Perancangan Arsitektur, Penerbit Erlangga Gunantara, N., Hartati, R.S., Dharma, A., Wijaya, I.K., Sukerayasa, W., Mataram, I.M., Pemayun, A.A.G.M., Sudiarta, P.K., (2016), Penataan Sistem Penerangan di Pura Beji Desa Les, Kecamatan Tejakula, Kabupaten Buleleng, Udayana Mengabdi, vol. 15, no. 1 .

Suryaningrum, (2018), Dasar-Dasar Konstruksi Bangunan, Penerbit Bumi Aksara Group 